\title{
Serum type I and type III procollagen peptide levels in sarcoidosis
}

\author{
L. Bacchella*, C. Tinelli**, L.S. Gilè+, V. Peona+, C. Aprile*, \\ M.Gorrini+, L. Pasturenzi+, G. Cetta ${ }^{++}$, M. Luisetti+
}

Serum type I and type III procollagen peptide levels in sarcoidosis. L. Bacchella, C. Tinelli, L.S. Gilè, V. Peona, C. Aprile, M.Gorrini, L. Pasturenzi, G. Cetta, M. Luisetti. (C) ERS Journals Ltd 1996.

ABSTRACT: Type I and type III are the most abundant collagens in the lung. The aim of our study was to compare type I and III procollagen peptides in sera of sarcoid patients.

Sixty eight patients with sarcoidosis were studied (19 with newly recognized disease, 7 with relapsing disease, 15 with chronic disease, and 27 in stable remission). Thirty healthy volunteers served as controls. The levels of procollagen I and III peptides were determined by radioimmunoassay. Angiotensin-converting enzyme (ACE) level was evaluated by means of a colorimetric assay.

In patients with newly recognized sarcoidosis, both serum procollagen I and III peptide levels were increased with respect to controls $(p=0.0014$ and $p<0.00001$, respectively). There was a poor correlation between levels of procollagen I and III $(r=0.26)$, whereas there was a closer correlation between procollagen III and ACE $(r=0.69)$. Procollagen I peptide level did not identify patients in roentgenological stage III.

In conclusion, in patients with newly recognized sarcoidosis there is a significant increase in the serum level of procollagen I peptide. However, procollagen I peptide is not a marker of sarcoid patients with fibrosis, i.e. stage III disease. Its clinical usefulness seems to be weaker than that of procollagen III peptide.

Eur Respir J., 1996, 9, 1648-1651.

\begin{abstract}
*Servizio di Medicina Nucleare, Fondazione Clinica del Lavoro, Pavia, Italy. **Unità di Statistica and +Istituto di Tisiologia e Malattie Respiratorie, IRCCS Policlinico San Matteo, Pavia, Italy. ${ }^{++}$Dipartimento di Biochimica, Università di Pavia, Italy.

Correspondence: M. Luisetti, Istituto di Tisiologia e Malattie Respiratorie, IRCCS Policlinico San Matteo, Università degli Studi di Pavia, Via Taramelli 5, 27100 Pavia, Italy
\end{abstract}

Keywords: Angiotensin-converting enzyme, collagens, granulomata, lung, sarcoidosis activity

\section{Received: May 121995}

Accepted after revision February 201996

This work has been partially supported by research grants from IRCCS Policlinico San Matteo (Ricerca Corrente) and from Fondazione Clinica del Lavoro.
Sarcoidosis is a multisystem granulomatous disorder characterized by an enhancement of immune processes at sites of disease activity [1]. A large variety of markers of disease activity have been proposed [2] for satisfactory assessment and clinical management of the disease.

Among biochemical markers, particular interest has been devoted to the search for indicators of accelerated turnover of extracellular matrix, with the purpose of using them to assess or predict fibrogenic processes in lung interstitium during sarcoidosis [3]. The most abundant macromolecules in the lung are the interstitial collagens [4]. Type I and type III are the most abundant of the lung collagens in normal conditions, with a ratio of $2: 1$. whereas, in fibrotic lungs there is an excess of type III collagen in the early stages and of type I in the late stages [5].

The availability of a radioimmunoassay for the $\mathrm{N}$ terminal procollagen III peptide (PIIINP) [6], a cleavage product of the type III procollagen molecule, makes it possible to demonstrate that PIIINP levels are increased in bronchoalveolar lavage (BAL) fluid $[7,8]$ and in serum $[9,10]$ of patients affected by sarcoidosis. However it is believed that such an elevation represents the expression of granulomata cell hyperactivity, rather than predicting fibrogenic processes.

More recently, a radioimmunoassay (RIA) able to determine the carboxyterminal propeptide of human type I procollagen (PICP) in biological fluids has been developed $[11,12]$. PICP is used as a marker of collagen biosynthesis in bone $[11,13,14]$, where type I collagen accounts for $>90 \%$ of the organic matrix.

Information about PICP in BAL fluids in interstitial lung disease (ILD) and sarcoidosis is so far very limited $[15,16]$. Its BAL fluid values increase similarly to those of PIIINP. However, no information about serum PICP in sarcoidosis is available.

The aim of our study was to evaluate the serum level of PICP, in comparison to that of PIIINP, in well-defined groups of patients with sarcoidosis.

\section{Material and methods}

\section{Study subjects}

The study comprised a series of 98 individuals, including 68 patients with biopsy proven sarcoidosis consecutively examined in our Department from April 1992 until September 1994. There were 43 females and 25 males and their mean age was $38 \pm 16$ yrs. The sarcoidosis patients were divided in four subsets: 1) newly diagnosed patients, 19 subjects (11 females and 8 males); 2) patients with relapse of the disease (recent worsening of chest radiograph and/or pulmonary function test parameters and/or dyspnoea, and increase of serum angiotensin converting 
enzyme (s-ACE) level), 7 subjects ( 6 females and 1 male); 3) patients with chronic sarcoidosis (persistent, but stable, chest radiographic abnormalities), 15 subjects (12 females and 3 males); and 4) patients in remission (persistent resolution of chest radiographic abnormalities), 27 subjects (14 females and 13 males). The patients had not received corticosteroid treatment for at least 6 months, with the exception of three patients with chronic sarcoidosis, chronically treated with oral prednisone $15 \mathrm{mg}$ on alternate day.

Thirty healthy volunteers from the clinical staff, 20 females and 10 males, mean age $36 \pm 12$ yrs, served as controls.

\section{Study design}

The study was designed as a cross-sectional investigation. The newly diagnosed patients and patients with relapse of the disease were assessed by chest radiograph, high resolution computed tomography (CT) scan, BAL, pulmonary function tests, $\mathrm{Ga}^{67}$ lung scan, abdomen ultrasonography and biopsy (either prescalenic, bronchial, transbronchial, or open lung). Biopsies were not performed in patients with relapse of the disease if histological proof had already been achieved. Subjects in remission and with chronic sarcoidosis were seen as out-patients and enrolled provided their clinical picture, chest radiograph, and pulmonary function test parameters were unchanged with respect to the previous examinations. Based on chest radiograph (independently reviewed by one radiologist and two pulmonologists), patients with newly diagnosed sarcodiosis, with relapse of the disease or with chronic sarcoidosis were assigned to roentgenological stage I, II, or III, according to DeReMEE [17].

Blood samples for determination of PICP, PIIINP, alkaline phosphatase, and s-ACE levels were obtained by venipuncture in control subjects and at the moment of disease assessment in patients with newly diagnosed sarcoidosis and relapse, or during examination in subjects in remission and with chronic sarcoidosis.

\section{Serum PICP, PIIINP and ACE level determination}

Aliquots of sera were kept at $-20^{\circ} \mathrm{C}$ for no more than 3 months before the determination of PICP, PIIINP, and ACE levels. A blood sample obtained at the same time had heparin added and was used immediately for the determination of alkaline phosphatase (assumed to be a serum marker of bone formation) [14] by standard automated methodology.

Serum PICP determination. The PICP level was determined by RIA (Procollagen, PICP [125I]; Farmos Diagnostica, Turku, Finland), based on the displacement of ${ }^{125}$ I-labelled PICP and the precipitation of the complex antigen-polyclonal antibody (raised in rabbit) by a solid-phase second antibody [12]. All samples were run in duplicate. The within and between assay variation coefficient was less than $10 \%$.

Serum PIIINP determination. The PIIINP level was determined by RIA (RIA-gnost PIIIP CIS International, Lif-surYvette, France), according to the manufacturer's instructions. The procedure is based on the principle of a two-stage sandwich assay, with the occurrence of a complex of solid-phase anti-PIIINP monoclonal antibodies raised in mouse, sample PIIINP, and ${ }^{125}$ I-labelled anti-PIIINP monoclonal antibodies raised in mouse. The monoclonal antibodies used in this kit are highly specific for Col 1-3 PIIINP, which accounts for approximately $20 \%$ of the total serum PIIINP level found in patients with IPF, the remainder being Col 1, a Col 1-3 metabolite [18]. The antibodies do not react with PICP. All samples were run in triplicate. The within and between assay variation coefficient was less than $8 \%$.

Serum ACE determination. The serum ACE level was determined by means of a colorimetric assay (ACE Color; Fujirebio Inc., Tokyo, Japan), using the substrate phydroxyhippuryl-histidyl-leucine [19], adjusted to a microassay [20].

\section{Statistical analysis [21]}

Data are presented as mean \pm SD. Differences in serum mean value of PICP, PIIINP, and ACE (quantitative variables), and roentgenological stage (qualitative variable) among groups were tested by one-way analyses of variance (ANOVA). Once overall differences were significant, least square differences (LSD) test for planned comparisons was used to identify which groups were responsible for the significance found. Relationships among quantitative variables were investigated by means of Pearson's correlation coefficient. The difference was taken as statistically significant at a p-level less than 0.05 . This analysis was approached as exploratory, rather than confirmatory, and no adjustments were made for multiple testing.

\section{Results}

The ANOVA showed that values of serum PICP, PIII$\mathrm{NP}$ and ACE were statistically different among the five groups of subjects studied $(\mathrm{F}=3.43, \mathrm{p}=0.011 ; \mathrm{F}=21.9$, $\mathrm{p}<0.0001 ; \mathrm{F}=7.1, \mathrm{p}=0.00035$, respectively). With reference to the PICP levels, patients with newly diagnosed sarcoidosis were found to be the only group of individuals with serum PICP levels significantly higher than those of the three other groups: their PICP level was higher than that of controls and patients with chronic or resolved sarcoidosis $(p=0.0014, p=0.0150$ and $p=0.0027$, respectively) (table 1). PICP level did not significantly

Table 1. - Serum PICP, PIIINP and ACE levels in the five groups of subjects

\begin{tabular}{lccc}
\hline & $\begin{array}{c}\text { PICP } \\
\mu \mathrm{g} \cdot \mathrm{L}^{-1}\end{array}$ & $\begin{array}{c}\text { PIIINP } \\
\mathrm{U} \cdot \mathrm{mL}^{-1}\end{array}$ & $\begin{array}{c}\mathrm{ACE} \\
\mathrm{U} \cdot \mathrm{mL}^{-1}\end{array}$ \\
\hline Controls $(\mathrm{n}=30)$ & $111 \pm 40$ & $0.48 \pm 0.04$ & $13.4 \pm 5.7$ \\
NDS (n=19) & $154 \pm 65^{*}$ & $0.86 \pm 0.26^{* *}$ & $26.3 \pm 9.9^{\ddagger}$ \\
RS $(\mathrm{n}=7)$ & $136 \pm 46$ & $0.74 \pm 0.09^{\$}$ & $26.3 \pm 9.3^{\#}$ \\
CS $(\mathrm{n}=15)$ & $116 \pm 33$ & $0.65 \pm 0.12^{\$ \$}$ & $23.7 \pm 9.6^{\# \#}$ \\
Res $(\mathrm{n}=27)$ & $113 \pm 39$ & $0.58 \pm 0.11^{\ddagger}$ & $16.7 \pm 3.6$
\end{tabular}

PICP: procollagen type I carboxyterminal propeptide; PIIINP: procollagen type III N-terminal peptide; ACE: angiotensin-converting enzyme; NDS: newly diagnosed sarcoidosis; RS: relapse of sarcoidosis; CS: chronic sarcoidosis; Res: resolution. *: $\mathrm{p}=0.0014$ vs controls, $\mathrm{p}=0.0027$ vs Res, $\mathrm{p}=0.0150$ vs CS; **. $\mathrm{p}<0.00001$ vs controls, $\mathrm{p}<0.0001$ vs Res, $\mathrm{p}=0.00004$ vs CS; $\$$ : $\mathrm{p}=0.00006$ vs controls, $\mathrm{p}=0.0128$ vs Res; $\$ \$$ : $\mathrm{p}=0.00064$ vs controls, $\mathrm{p}=0.00004$ vs NDS; $: \mathrm{p}=0.01270$ vs controls; vs controls, $\mathrm{p}=0.00009$ vs Res; \#: $\mathrm{p}<0.00001$ vs controls, $\mathrm{p}=0.0053$ vs Res; \#\#: $\mathrm{p}=0.0009$ vs controls, $\mathrm{p}=0.0073$ vs Res. 


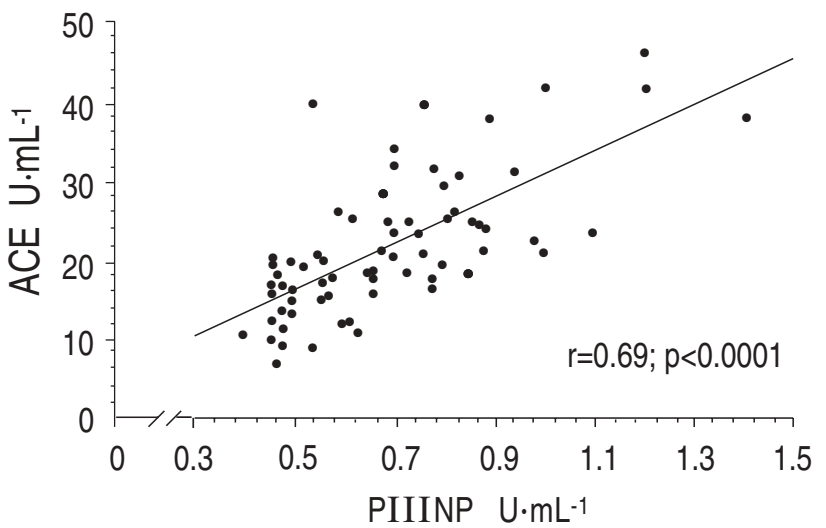

Fig. 1. - Relationship between serum procollagen type III N-terminal propeptide (PIIINP) and angiotensin-converting enzyme (ACE) values in the 68 patients with sarcoidosis.

differ between patients with newly diagnosed sarcoidosis and patients with relapse. In the overall series of sarcoid patients, a good correlation was found between serum PIIINP and ACE ( $r=0.69$; fig. 1$)$. In contrast, a poor correlation was found between serum PICP and PIIINP $(\mathrm{r}=0.26)$. There was no correlation between serum PICP and ACE.

No significant correlation was found between serum PICP and PIIINP levels and roentgenological stage of the disease. Figure 2 shows the scattergram of serum PICP levels in 41 patients with sarcoidosis in which the roentgenologic stage could be given (i.e. newly diagnosed sarcoidosis, relapse and chronic sarcoidosis groups). There was no difference in serum PICP levels among patients in stage I $(n=13)$, stage II $(n=10)$, or stage III $(n=18)$. In particular, stage III patients, i.e. patients with interstitial fibrosis, had slightly lower serum PICP levels than those of the other two stages.

The mean serum level of alkaline phosphatase in patients with newly diagnosed sarcoidosis did not significantly differ from that of the controls $(157 \pm 46$ vs $\left.185 \pm 77 \mathrm{mU} \cdot \mathrm{mL}^{-1}, \mathrm{NS}\right)$.

\section{Discussion}

The main issue addressed by our study is that in the serum of patients with newly diagnosed sarcoidosis the

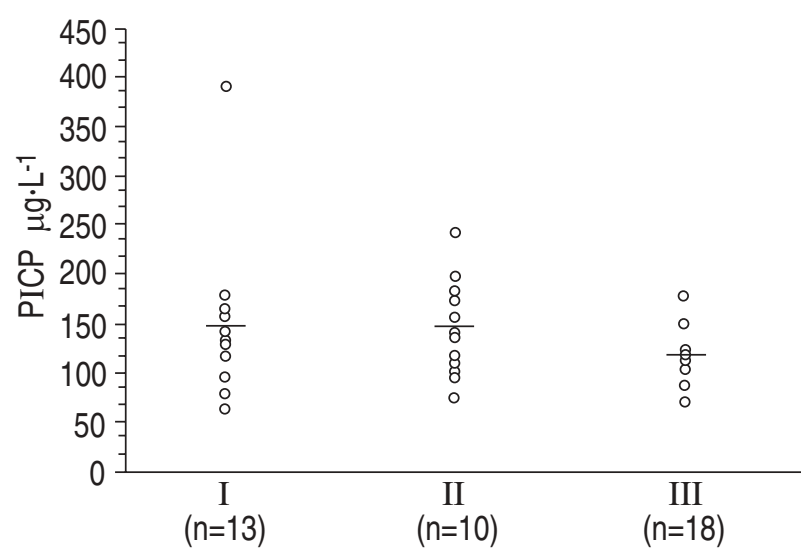

Fig. 2. - Scattergram of serum procollagen type I carboxyterminal propeptide (PICP) levels as a function of the roentgenological stage in patients with newly diagnosed sarcoidosis $(n=19)$, relapse of the disease $(n=7)$, and chronic sarcoidosis $(n=15)$. Mean PICP value (horizontal bar) did not significantly differ between the three stages. level of PICP is significantly increased with respect to control subjects. The PICP value also discriminates between patients with new diagnosis and patients whose disease is in stable remission or is chronically active, but not patients affected by relapsing sarcoidosis (table 1). This evidence would suggest that, in patients with florid disease, accelerated metabolism of type I collagen occurs.

Though organic matrix of bone is the major source of PICP in healthy conditions, the origin of the increased serum PICP level from thoracic granulomata is suggested by the following: 1) serum level of PICP in controls of the same age and sex distribution is low (table 1);2) we found normal serum levels of alkaline phosphatase, assumed to be a marker of bone formation, as well as PICP [14], in those patients with newly recongnized sarcoidosis with the highest serum PICP levels; 3) mild bone mineral loss has been found only in patients with longstanding (>20 months) untreated sarcoidosis [22]; and 4) an increased level of PICP has also been detected in BAL fluid of patients with sarcoidosis $[15,16]$. Increased serum PICP level has been detected in patients with alcoholic liver disease [23], in a phase preceding the occurrence of hepatic fibrosis. Though liver is often involved in sarcoidosis, none of the patients from our series had a biopsy ascertained liver localization or showed alteration of hepatic function indices.

As happens for other products of the extracellular matrix components, such as hyluronan and PIIINP [3], so too PICP might be considered as a potential marker of fibrosis, and could be a more realistic candidate, since lung collagen content shifts towards type I collagen in a late phase of interstitial lung disease, i.e. fibrotic lung [5]. However, our finding that the serum PICP level in stage III sarcoid patients is not different from that of stage I and II patients (fig. 2) would deny this possibility, thus paralleling the evidence obtained by us [9] and others [10] for serum PIIINP level. Increased values of PIIINP do not necessarily mean an increased synthetic process, since it is known that not all of the $\mathrm{N}$-terminal peptide of type III procollagen is removed, but it may be cleaved from the extracellular matrix [24]. In this context, PIIINP value is believed rather to be an index of accelerated type III collagen turnover. Although with a lower significance level, behaviour of serum PICP in sarcoidosis parallels that of serum PIIINP, suggesting that the metabolism of both types of collagen is accelerated. A similar occurrence has been shown for PIIINP and type VI collagen related peptide in BAL fluid of sarcoid patients [25].

In conclusion, we have demonstrated that in patients with newly diagnosed sarcoidosis there is a significant increase in the serum level of procollagen type I carboxyterminal peptide. However, from our data we conclude that serum procollagen type I carboxyterminal peptide level, in comparison to that of serum N-terminal procollagen III peptide, does not add substantially to our knowledge about the turnover of extracellular matrix component in sarcoidosis, and that its clinical usefulness is very limited.

\section{References}

1. Thomas PD, Hunninghake GW. Current concepts of the pathogenesis of sarcoidosis. Am Rev Respir Dis 1987; 135: 747-760. 
2. Costabel U, du Bois R, Eklund A, et al. Consensus conference: activity of sarcoidosis. Eur Respir J 1994; 7: 624-627.

3. Costabel U. Biochemistry. In: James DG, ed. Sarcoidosis and Other Granulomatous Disorders. Lung Biology in Health and Disease. Vol. 73. New York, Dekker, 1994: 429-463.

4. Mayne R, Brewton RG. New members of the collagen superfamily. Curr Opin Cell Biol 1993; 5: 883-890.

5. Laurent GJ. Lung collagen: more than scaffolding. Thorax 1986; 41: 418-428.

6. Rhode H, Vargas L, Hahn E, Kalbfleisch H, Bruguera M, Timpl R. Radioimmunoassay for type III procollagen peptide and its application to human liver disease. Eur J Clin Invest 1979; 9: 451-459.

7. Low RB, Cutroneo KR, Davis GS, Giancola MS. Lavage type III procollagen $\mathrm{N}$-terminal peptides in human pulmonary fibrosis and sarcoidosis. Lab Invest 1983; 48: 755-759.

8. Bjermer L, Thunell M, Hallgren R. Procollagen III peptide in bronchoalveolar lavage fluid; a potential marker of altered collagen synthesis reflecting pulmonary disease in sarcoidosis. Lab Invest 1986; 55: 654-656.

9. Luisetti M, Bulgheroni A, Bacchella L, Pasturenzi L, Aprile C. Elevated serum procollagen III aminopeptide levels in sarcoidosis. Chest 1990; 98: 755-759.

10. Pohl WR, Thompson AB, Kohn H, et al. Serum procollagen III peptide levels in subjects with sarcoidosis: a 5 year follow-up study. Am Rev Respir Dis 1992; 145: 412-417.

11. Carey DE, Goldberg B , Ratzan SK, Rubin KR, Rowe DW. Radioimmunassay for type I procollagen in growth hormone-deficient children before and during treatment with growth hormone. Pediatr Res 1985; 19: 8-11.

12. Melkko J, Niemi S, Risteli L, Risteli J. Radioimmunassay of the carboxyterminal propeptide of human type I procollagen. Clin Chem 1990; 36: 1328-1332.

13. Parfitt AM, Simon LS, Villanueva AR, Krane SM. Procollagen type I carboxy-terminal extension peptide in serum as a marker of collagen biosynthesis in bone: correlation with iliac bone formation tares and comparison with total alkaline phosphatase. J Bone Miner Res 1987; 2: 427-436.
14. Hodsam AB, Fraher LJ, Ostbye T, Adachi JD, Steer BM. An evaluation of several biochemical markers for bone formation and resorption in a protocol utilizing cyclical parathyroid hormone and calcitonin therapy for osteoporosis. J Clin Invest 1993; 91: 1138-1148.

15. Curull C, Segura RM, Morell F, de Garcia X, Pascual C. Type I and type III procollagen peptides in serum and bronchoalveolar lavage in sarcoidosis and hypersensitivity pneumonitis. Am J Respir Crit Care Med 1994; 149: A606 (Abstract).

16. Tukiainen P, Risteli J, Salonen EM, Laitinen T, Taskinen E. Procollagen-III-N-terminal (PIIINP) and I-C-terminal (PICP) peptides are not markers of fibrosis in sarcoidosis. Sarcoidosis 1994; 11: 84 (Abstract).

17. DeRemee RA. The chest roentgenology of sarcoidosis. In: Lieberman J, ed. Sarcoidosis. Orlando, Grune \& Stratton, 1985; pp. 117-135.

18. Harrison NK, McAnulty RJ, Kimpton WG, Fraser JRE, Laurent TC, Laurent GJ. Heterogeneity of type III procollagen N-terminal peptides in BAL fluid from normal and fibrotic lungs. Eur Respir J 1993; 6: 1443-1448.

19. Kasahara Y, Ashihara Y. Colorimetry of angiotensin-Iconverting enzyme activity in human. Clin Chem 1981; 27: 1922-1925.

20. Arbustini E, Grasso M, Leo G, et al. Polymorphism of angiotensin-converting enzyme gene in sarcoidosis. Am J Respir Crit Care Med 1996; 153: 851-854.

21. Armitage P. In: Statistical Methods in Medical Research. London, Blackwell, 1971.

22. Montemurro L, Fraioli P, Rizzato G. Bone loss in untreated longstanding sarcoidosis. Sarcoidosis 1991; 8: 29-34.

23. Savolainen E-R, Goldberg B, Leo MA, Lieber CS. Diagnostic value of serum procollagen peptide measurements in alcoholic liver disease. Alcohol Clin Exp Res 1984; 8: 384-389.

24. Risteli L, Risteli J. Radioimmunoassay for monitoring connective tissue metabolism. Rheumatology 1986; 10: 216-245.

25. Schaberg T, Orzechowski K, Oesterling C, Lode H, Schuppan D. Simultaneous measurement of collagen typeVI-related antigen and procollagen type-III-N-propetide levels in bronchoalveolar lavage. Eur Respir J 1994; 7 : 1221-1226. 